\title{
PAZ6 cells constitute a representative model for human brown pre-adipocytes
}

\section{Melissa Kazantzis ${ }^{1}{ }^{*}$, Virginia Takahashi ${ }^{1}$, Jessica Hinkle ${ }^{1}$, Smitha Kota ${ }^{1}$, Vladimir Zilberfarb ${ }^{2,3,4}$, Tarik Issad ${ }^{2,3,4}$, Mouaadh Abdelkarim ${ }^{5}$, Lotfi Chouchane ${ }^{5}$ and Arthur Donny Strosberg ${ }^{1,2,6}$}

\author{
Department of Infectology, The Scripps Research Institute-Florida, Jupiter, FL, USA \\ 2 INSERM U1016, Paris, France \\ ${ }^{3}$ CNRS-UMR8104, Paris, France \\ ${ }^{4}$ Département de Biologie Cellulaire, Université Paris Descartes, Paris, France \\ ${ }^{5}$ Department of Genetic Medicine, Weill Cornell Medical College in Qatar, Doha, Qatar \\ ${ }^{6}$ Institut Cochin INSERM U1016, Université Paris7-Denis-Diderot, Paris, France
}

\section{Edited by:}

Toru Hosoi, Hiroshima University, Japan

Reviewed by:

Marta Letizia Hribal, University of Catanzaro Magna Graecia, Italy

Marimelia Porcionatto, Universidade Federal de São Paulo, Brazil

${ }^{*}$ Correspondence:

Melissa Kazantzis, Department of Infectology, The Scripps Research Institute-Florida, 120 Scripps Way, \#B110, Jupiter FL, 33458, USA. e-mail:mkazantz@scripps.edu
The role of brown adipose tissue (BAT) in human metabolism and its potential as an antiobesity target organ have recently received much renewed attention. Following radiological detection of substantial amounts of BAT in adults by several independent research groups, an increasing number of studies are now dedicated to uncover BAT's genetic, developmental, and environmental determinants. In contrast to murine BAT, human BAT is not present as a single major fat depot in a well-defined location. The distribution of BAT in several areas in the body significantly limits its availability to research. A human brown adipocyte cell line is therefore critical in broadening the options available to researchers in the field. The human BAT-cell line PAZ6 was created to address such a need and has been well characterized by several research groups around the world. In the present review, we discuss their findings and propose potential applications of the PAZ6 cells in addressing the relevant questions in the BAT field, namely for future use in therapeutic applications.

Keywords: obesity, brown adipocytes, cell lines, PAZ6 cells

\section{INTRODUCTION}

\section{THE ROLE OF BROWN AND WHITE ADIPOCYTES IN METABOLISM}

The continuous rise in the incidence of world-wide obesity reflects the persistent lack of efficient treatment strategies. Obesity results when energy intake exceeds energy expenditure on a regular basis (National Institutes of Health, 2010; World Health Organization, 2010). Excess calories are stored as single intracellular triacylglycerol (TG) droplets in white adipose tissue (WAT), the organism's largest reserve of energy. Conversely, brown adipose tissue (BAT) shifts the energy balance toward expenditure. BAT dissipates the energy resulting from the catabolism of glucose and fatty acids using uncoupling protein 1 (UCP1)-mediated thermogenesis. In rodents kept in cold, despite comprising only a few percent of the body weight, BAT may reduce more than $50 \%$ of all the oxygen inhaled/food consumed and hence, dissipate chemical energy of same magnitude (Cannon and Nedergaard, 2011; Nedergaard et al., 2011).

As expected from their distinct physiological roles, WAT and BAT were shown to derive from different precursor cells (Seale et al., 2008). While WAT cells originate in the lateral plate mesoderm, from pericyte-like cells associated with blood vessels, BATcells share with myocytes a common Myf5+ precursor originated in the dermomyotome derived from the paraxial mesoderm (Seale et al., 2008). The transcriptional regulator PRDM16 (PRD1-BF1RIZ1 homologous domain containing 16) was shown to determine the brown fat fate of the Myf5-positive precursors (Seale et al., 2008). Additionally, UCP1-positive cells can arise in WAT under certain conditions (cold exposure, for example). These cells have been designated as "brite" and although they express UCP1 at much lower levels than BAT adipocytes, they do not possess many features of "classic" BAT-cells (Waldén et al., 2012). Besides Myf5, present in BAT but not "brite precursors," the molecular markers homeobox C9 (Hox9) and Zinc fingers in the cerebellum 1 (Zic1) also display adipose depot-dependent expression. Zic1 is only expressed in "classic" BAT while Hox9 is expressed in both "brite" and WAT, but not BAT (Waldén et al., 2012).

\section{BAT DETECTION IN HUMANS}

Although it was long considered that the prominent BAT depots of newborns were progressively lost with age, to end up being supposedly absent from human adults, a combination of positron emission and computer tomography (PET/CT) data from a number of studies originally done to detect metabolically active tumors, recently confirmed by dedicated analyzes that a significant proportion of adult humans may actually possess significant amounts of physiologically relevant BAT (Nedergaard et al., 2007; Cypess et al., 2009; van Marken Lichtenbelt et al., 2009; Orava et al., 2011). The prevalence in pediatric patients is nevertheless, still several fold higher than in adults, although an increase in BAT may occur from childhood to adolescence in both boys and girls, as measured by CT Hounsfield Units of X-ray attenuation's (HU) and PET (Gilsanz et al., 2011).

Positron emission and computer tomography scans have become indisputably the gold-standard in BAT detection. However, the requirement for radiolabeled tracers limits its use. ${ }^{8} \mathrm{~F}$-2-fluoro-2-deoxyglucose (F-DG) is typically used and its signal 
is only detected in metabolically active cells. This caveat has lead to growing interest in alternative BAT detection techniques. The feasibility of using magnetic resonance imaging (MRI) and magnetic resonance spectroscopy (MRS) for BAT detection is discussed elsewhere (Hu and Gilsanz, 2011). Of particular note, the distinction of BAT from WAT has been achieved based on their relative fat contents, which produce different signal patterns in chemicalshift-water-fat separation MRI (Hu et al., 2010a,b). Additionally, BAT and WAT were also shown to appear in non-overlapping regions in the HU scale (BAT displaying greater attenuation due to its higher vascularization and water content), even though both tissues are $\mathrm{HU}$-negative and therefore distinguishable from bone and all other HU-positive soft tissues (Hu et al., 2011).

With the repeated detection and the general acceptance of the presence of substantial BAT in most human adults, a BAT-based route of pharmacologic intervention against obesity may now become more feasible.

\section{PHYSIOLOGICAL RELEVANCE OF BAT IN HUMANS}

While there is a large quantity of studies supporting the importance of BAT metabolism to body weight in rodents, the literature is scarce in studies done in humans. Still, the inverse relationship between BMI and BAT found repeatedly in recent studies and in PET/CT scans analyzed retrospectively (see reviews by Betz and Enerbäck, 2011 and van Marken Lichtenbelt, 2011), suggest that BAT could be protective against weight gain in humans.

Functionally, results from an in vivo analysis of adult human BAT (Orava et al., 2011) parallel previous findings in rodents (Bartelt et al., 2011). By combining PET/CT imaging, blood tests and gene expression from biopsies, human volunteers were shown to respond to cold exposure with a remarkable 12-fold increase in glucose uptake, accompanied by a doubling in BAT perfusion rate, well correlated with the subjects' metabolic rates (Orava et al., 2011).

The PET scans from 10 healthy men show an average BAT volume of $130 \mathrm{~cm}^{3}$, which corresponds to tens of grams of tissue (Saito et al., 2009; van Marken Lichtenbelt et al., 2009). When exposed to the cold $\left(16^{\circ} \mathrm{C}\right.$ for $2 \mathrm{~h}$ ), these subjects showed increased metabolic rate, concomitant with BAT activation, reflected in the increased F-DG uptake.

Quantitative estimations of the potential metabolic impact of BAT to whole body energy expenditure in humans were extrapolated from observations in rodents and considerations on human BAT mass have been made upon analysis of F-DG PET/CT scans. Based on the maximal heat-producing capacity of $300 \mathrm{~W} / \mathrm{kg}$ suggested for the mouse, $50 \mathrm{~g}$ of maximally stimulated BAT (which can occur physiologically in humans) could dissipate daily 3-5\% extra calories (Rothwell and Stock, 1981). This caloric deficit could translate to a loss of approximately $4 \mathrm{~kg}$ ( $\sim 9$ pounds) in the adult yearly weight.

Though preliminary, the physiological data obtained to date points toward the potential benefits of BAT in human health. Therefore, maximizing BAT amounts and mimicking cold activation pharmacologically may constitute effective combined strategies against weight gain and the associated complications of obesity. Before getting so far, there is an urgency to develop and evaluate human brown adipocyte models as essential tools for the discovery of molecular targets to modulate BAT viability, proliferation, and activation.

\section{BAT-DERIVED CELL LINES FROM RODENTS}

Hibernomas grown in p53 Knock Out mice or SV40 large T antigen transgenic mice have been used to generate immortalized murine BAT-cell lines (defined by UCP1 gene expression) such as the T37i (Penfornis et al., 2000), the HIB-1B (Ross et al., 1992), and the HB2 (Irie et al., 1999) cell lines (see review by Klein et al., 2002). These in vitro systems have helped acquire substantial knowledge of murine BAT biology.

\section{THE NEED FOR HUMAN ADIPOCYTE IN VITRO MODELS}

Striking differences between the thermogenic requirements of mice and humans limit however the extent to which the findings in animals can be extrapolated to the human situation. Such differences are well illustrated by the fact that while clothed humans consume food equivalent to only about $2 \%$ of their total body energy content, a laboratory mouse living at $24^{\circ} \mathrm{C}$ will consume approximately $50 \%$ of its total body energy content daily, and will dedicate a large proportion of this energy to BAT heat production. If food is scarce, mice enter into torpor, an adaptive drop in body temperature and reduced metabolic rate, not seen in humans (Himms-Hagen, 1999). This increased need for BAT-generated heat is directly correlated with the higher surface-to-body mass ratios of smaller mammals (Himms-Hagen, 1999).

A number of comparative studies highlight significant differences in the genetic, metabolic, and physiologic make-up of adipose tissue among species.

For example, the genes for Type II iodothyronine deiodinase (DIO2), peroxisome-proliferator-activated receptor $1 \alpha(\mathrm{PGC} 1 \alpha)$ and PRDM16 have been shown to be highly enriched in the murine BAT versus WAT but only slightly more abundant in the human BAT versus WAT (Svensson et al., 2011).

Notably, the degree of white adipocyte responsiveness to the selective $\beta 3$ adrenergic agonists BRL37344 and CGP12177 (relative to isoproterenol) was shown to inversely correlate with animal size. Rats and hibernators such as golden hamsters and dormouse were shown to be hyper-responders, medium-size mammals such as rabbits and dogs were weak-responders, and monkeys and men were reported to be either very weak or non-responders (Lafontan and Berlan, 1993).

Another distinguishing parameter in the lipid metabolism of mice and men is the predominant lipoprotein class carrying cholesterol: low-density lipoproteins (LDL) in humans, high-density lipoproteins (HDL) in rodents (Vitic and Stevanovic, 1993).

Finally, the shared amino acid identity of mouse and human UCP1 is less than $80 \%$. The rodent UCP1 kinetics has been extensively studied in a variety of expression systems. Isolated mitochondria, liposomes, lipid bilayers, yeast, cell lines, and tissue have been used. A comparative table displaying the results for the membrane potential, UCP1 protein concentration, and the rates of proton transport of each system can be found in the review by Hirschberg et al. (2011). In contrast, no study on human UCP1 kinetics has been performed to date. 
In view of such species-dependent variations, studies ultimately aimed at being translated into the clinics must ideally be conducted on human cellular models of white and BAT whenever available. Additionally, the specific lack of studies on human UCP1 kinetics urgently calls for a human brown adipocyte cell line (or precursor cell line) with the obvious advantage of allowing this system to be characterized in its native environment.

\section{HUMAN ADIPOCYTE-LIKE CELL LINES}

Biopsies of spontaneous tumors have provided a source of immortalized precursor cells that can be differentiated into white adipocytes in vitro (Table 1). The Lisa-2 cells (Wabitsch et al., 2000) and the LS-14 cells (Hugo et al., 2006) were obtained from patients with liposarcoma. The AML-I cells (Torii et al., 2003) were derived from peripheral blood mononuclear cells from a patient with acute myeloid leukemia. Another white preadipocyte cell line, which continuously proliferates in culture, was obtained from a patient with the Simpson-Golabi-Behmel syndrome (Wabitsch et al., 2001). The Chub-S7 cell line (Darimont et al., 2003) was derived from subcutaneous white adipose and immortalized with the human telomerase reverse transcriptase (hTERT) and the papillomavirus E7 oncoprotein (HPV-E7; Table 1).

In contrast to the general availability of peripheral subcutaneous or omental tissues and of occasional occurrence of liposarcomas (Wibmer et al., 2010), hibernoma, or pheochromocytoma tumors associated with well-localized BAT depots are extremely rare (Lath et al., 2011), probably explaining why there are no reports on immortalized cell lines of such origin in the literature.

Stromal vascular cells obtained from adult human biopsies following F-DG PET/CT scans were recently shown to differentiate in vitro into UCP1-positive adipocytes. This study confirms unequivocally the presence of potential BAT-cell precursors in the supraclavicular region in humans independent of their FDG PET/CT status, as both PET-negative and positive biopsies provided UCP1-positive cells (Lee et al., 2011).

Although human primary stem cells that differentiate into brown adipocytes in vitro can now be routinely obtained, an obvious caveat is that they cannot be propagated beyond a few cell passages and cannot be easily compared between individuals due to expected genetic variations.

\section{THE PAZ6 CELL LINE} ORIGIN

The PAZ6 cell line was obtained from the vascular stromal fraction from human infant BAT and immortalized through transfection with the genes coding for the SV40 T and $\mathrm{t}$ antigens under the control of the vimentin promoter (Zilberfarb et al., 1997). It fulfills the condition of an immortalized human cell model with the ability to differentiate into brown adipocytes in culture.

\section{UCP1 DETECTION}

Uncoupling protein 1 was shown by qPCR and Northern Blot to be present in differentiated PAZ6 cells and to be further induced by norepinephrine (NE; Figure 1). Presence of this BAT-exclusive protein is a required criterion for defining BAT.

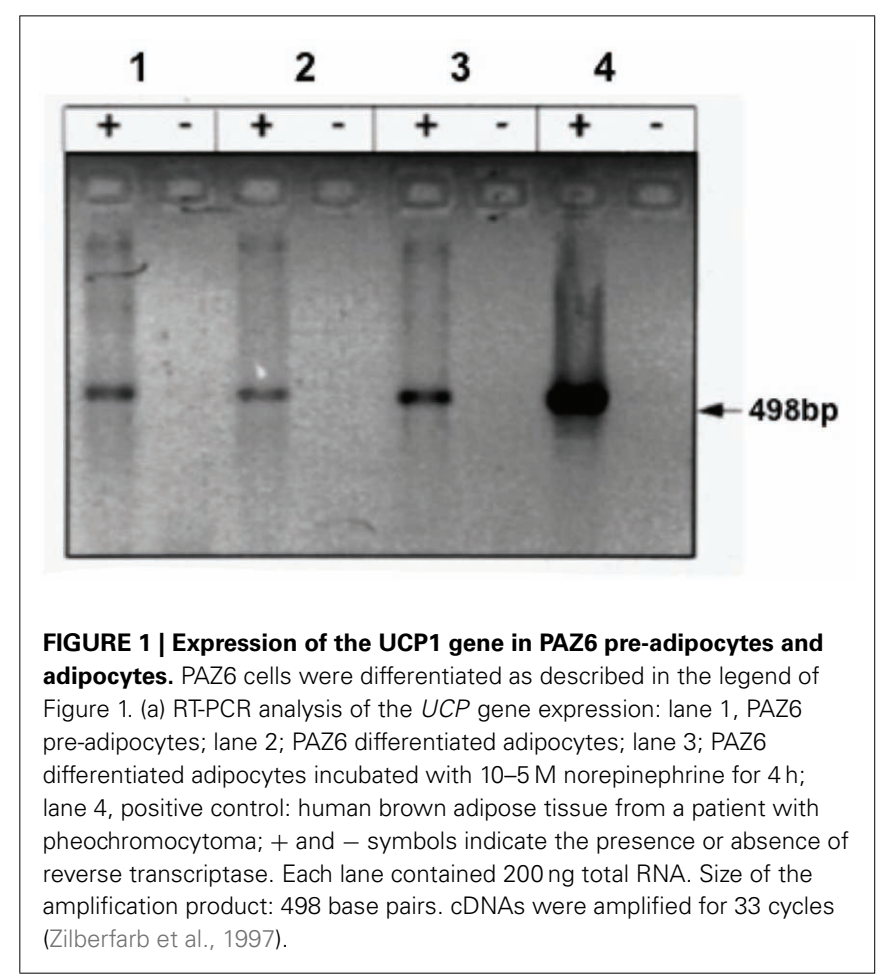

Table 1 | Human adipocyte cell lines.

\begin{tabular}{|c|c|c|c|}
\hline Cell line & White or brown & Immortalization method & Reference \\
\hline Lisa & White & Spontaneous tumor (liposarcoma) & Wabitsch et al. (2000) \\
\hline LS-14 & White & Spontaneous tumor (liposarcoma) & Hugo et al. (2006) \\
\hline $\mathrm{AML}-1$ & White & Spontaneous tumor (leukemia) & Torii et al. (2003) \\
\hline SGBS & White & Simpson-Golabi-Behmel syndrome & Wabitsch et al. (2001) \\
\hline Chub-S7 & White & $\begin{array}{l}\text { Telomerase reverse transcriptase and } \\
\text { papillomavirus E7 oncoprotein transformed }\end{array}$ & Darimont et al. (2003) \\
\hline SVF from supra-clavicular fat & Brown* & None & Lee et al. (2011) \\
\hline Primary stem cells & Brown* & None & Morganstein et al. (2010), Elabd et al. (2009) \\
\hline PAZ6 & Brown* & SV40 T and t antigens transformed & Zilberfarb et al. (1997) \\
\hline
\end{tabular}

${ }^{*}$ Expressing UCP1. 
This UCP1-expressing human cell line may enable the characterization of human UCP1 in its "normal" environment and may help support the concept that "BAT can counteract obesity in humans." However immortalization and advanced passaging can alter the cell phenotype (Hirschberg et al., 2011). Uncoupling activity may be down-regulated upon continuous propagation of cells in vitro since UCP-mediated thermogenesis results from physiologic adaptation in whole animal, in a sympathetic-dependent manner (Festuccia et al., 2010). Drugs that promote UCP1 gene expression have been successfully used to overcome this in vitro caveat.

Technical issues aside, UCP1 concentration in human BAT may be several fold lower than in rodents (Lean et al., 1986), predicting low UCP1 in future human cellular models. Proper normalization will be essential to correct species-associated differences in absolute UCP1 content and total levels should be accounted for in estimations concerned with metabolic significance.

\section{CHARACTERIZATION OF THE HUMAN BROWN ADIPOCYTE CELL LINE PAZ6}

Continuous characterization of the PAZ6 brown adipocytes since their initial development in 1997 (Zilberfarb et al., 1997) has revealed the expression of several key adipogenic markers. The cells have also been employed as an in vitro model for the study of adipose-specific processes, such as leptin secretion and nuclear receptor-dependent gene expression (Bailleul et al., 1997; Grosfeld et al., 2002; Oberkofler et al., 2002, 2004a,b) in addition to simply being utilized as a "host" in vitro vessel for studies of generic cellular processes (Esterbauer et al., 2000, 2001; Hazan et al., 2002;
Tang et al., 2008). These additional findings and their relevance to a better understanding of (brown) adipose tissue biology are discussed here.

\section{ADIPOGENIC MARKERS}

The 14 days differentiation cocktail described by Zilberfarb et al. (1997) was shown to up-regulate the genes for $\beta_{1}, \beta_{2}$, and $\beta_{3}$ adrenergic receptors $(\beta-\mathrm{AR})$, hormone sensitive lipase (HSL), lipoprotein lipase (LPL), adipsin, glucose transporters 1 and 4 (GLUT 1 and 4), and leptin. The mRNA's of adipocyte-positive TNF$\alpha$ receptors, TNFR1 and TNFR2 are also detected in confluent PAZ6 (Zilberfarb et al., 2001). The expression of such genes parallels the progressive accumulation of multilocular fat stores in the cytosol of PAZ6 cells (Figure 2; Zilberfarb et al., 1997) and display expression kinetics comparable to human primary adipocytes (Figure 3).

Treatment with the $\beta_{3}$-AR agonist CGP12177A, a $\beta_{1}$ and $\beta_{2}$ antagonist (Blin et al., 1994), promotes glycerol release by PAZ6 adipocytes at levels comparable to forskolin, NE, or isoproterenol (Zilberfarb et al., 1997), confirming that coupling of the $\beta_{3}$-AR to lipolysis is intact in PAZ6. The $\beta_{3}$ is the predominant AR subtype detected in PAZ6 cells (75\% of the total $\beta$-AR binding; Jockers et al., 1998), an important feature also seen in the membranes of brown adipocytes obtained from a BAT capsule growing around a pheochromocytoma adrenal gland tumor. Similar to brown adipocytes and differentiated peritumoral precursors pre-treated with NE for several hours, PAZ6 $\beta_{3}$-AR signaling undergoes desensitization (Jockers et al., 1998), in part due to the down-regulation in receptor number (Jockers et al., 1998).
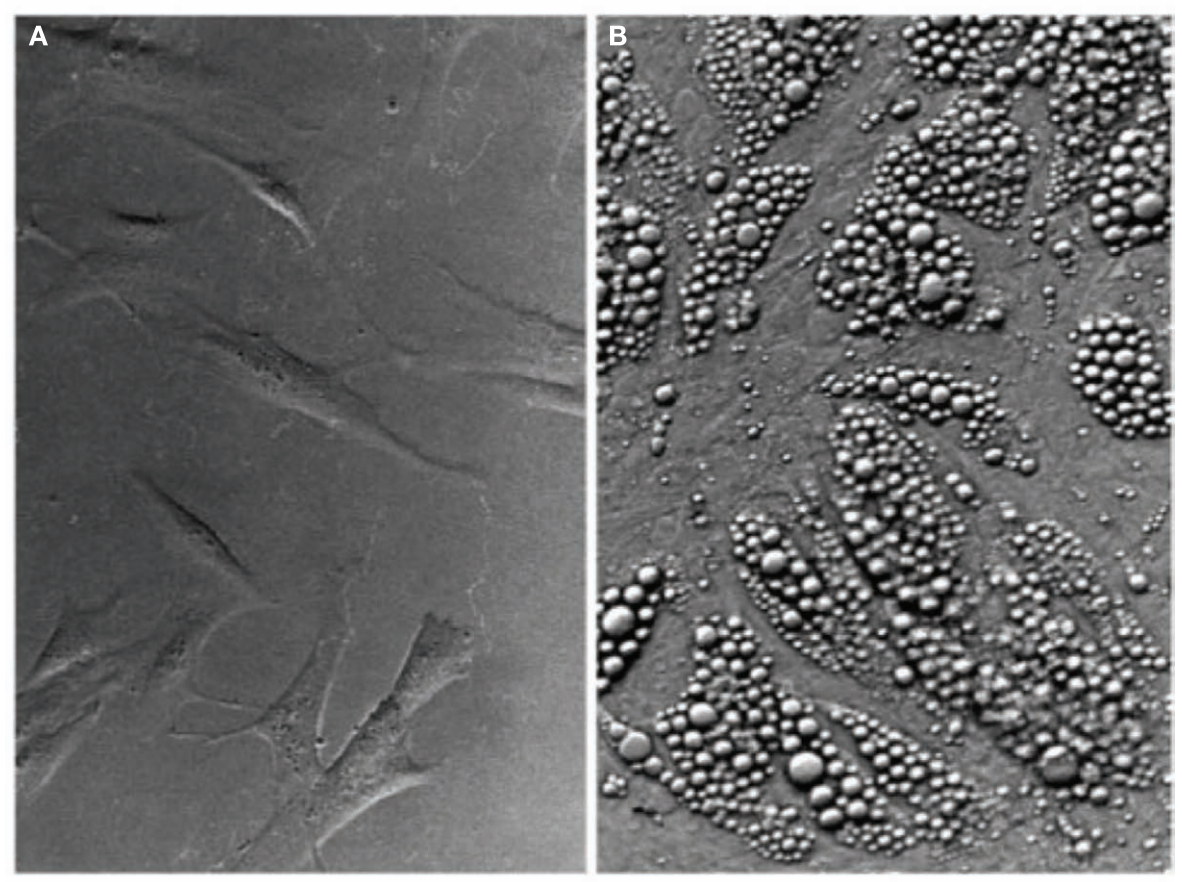

FIGURE 2 | Multilocular lipid accumulation in PAZ6 adipocytes upon differentiation. (A) PAZ6 pre-adipocytes in culture. (B) Differentiated PAZ6 adipocytes. Differentiation was carried out for 3 weeks in propagation medium supplemented with $1 \mathrm{nMT}_{3}, 850 \mathrm{nM}$ insulin, $100 \mathrm{nM}$ dexamethasone, and $1 \mu \mathrm{M}$ pioglitazone (Zilberfarb et al., 1997). 


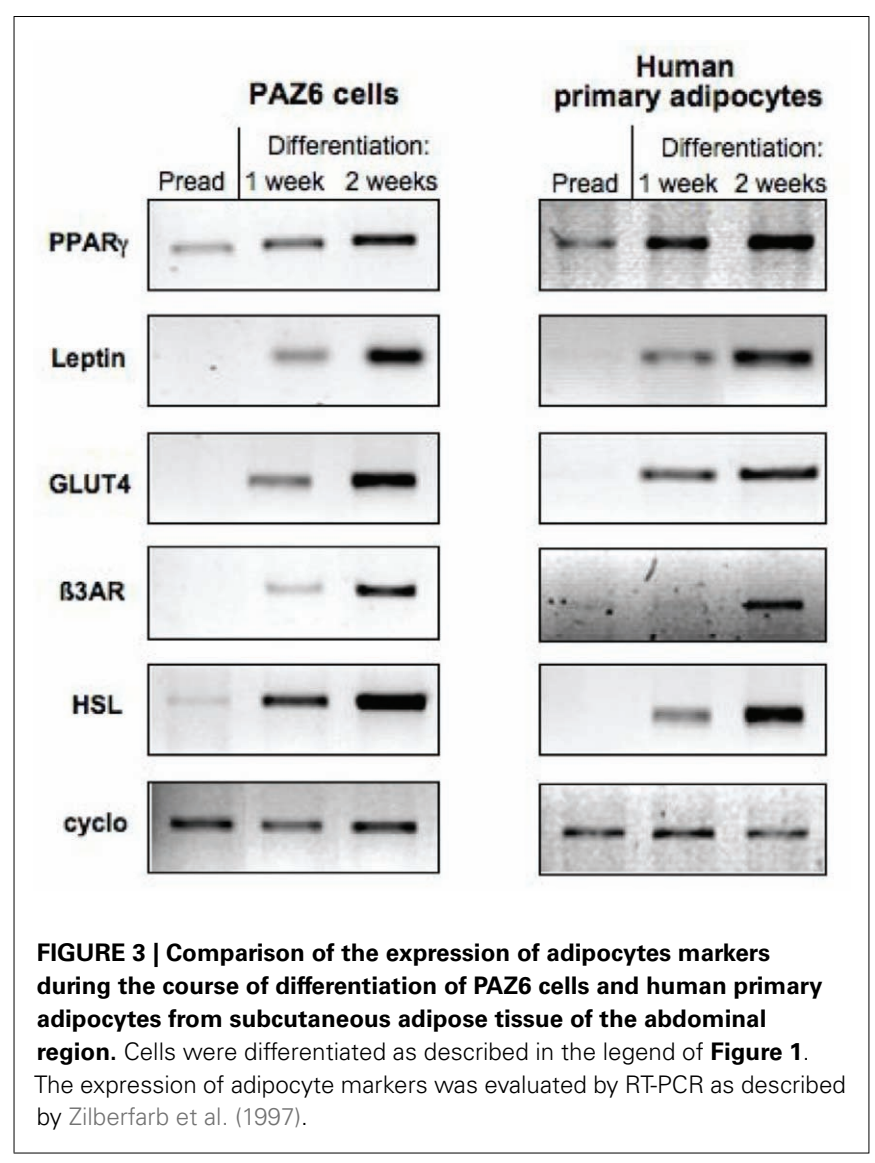

The melatonin receptor $1 \mathrm{~b}$ isoform (MT2), earlier found in BAT and WAT, is expressed in PAZ6 cells (Brydon et al., 2001). There, melatonin doses around the physiological $\mathrm{IC}_{50}$ were shown to be inhibitory to forskolin-dependent rise in cyclic adenosine monophosphate (cAMP; Brydon et al., 2001).

Also resembling other adipocyte in vitro models (Tontonoz and Spiegelman, 2008), PAZ6 differentiation was shown to respond to the thiazolidinediones: naphthylazo (5-[2-(2-naphthylmethyl)5-benzofuranylmethyl]-2,4-thiazolidinedione) or pioglitazone (5[4-[2-(5-ethyl-2-pyridyl)ethoxy]benzyl]-2,4-thiazolidinedione) with up-regulation of the classic adipose-marker adipocyte protein 2 (aP2) and also of the genes coding for the adipogenicassociated proteins-peroxisome proliferator-activated receptor gamma (PPAR $\gamma$ ), $\beta_{3}$-AR, HSL, and uncoupling protein 2 (UCP2; Strobel et al., 1999). Moreover, PAZ6 respond to dexamethasone with up-regulation of the fat-metabolism-related genes for CCAAT-enhancer-binding proteins alpha $(\mathrm{C} / \mathrm{EBP} \alpha), \operatorname{PPAR} \gamma$, LPL, and leptin (Zilberfarb et al., 2001) in a dose-dependent manner.

The levels of the adipokine leptin expressed and secreted by PAZ6 were shown to be remarkably comparable to human primary adipose cells. Leptin levels responded to low oxygen concentration culturing or chemically induced hypoxia with a two to threefold induction in expression. The hypoxia-inducible GLUT1 was upregulated as expected and, not surprisingly, GLUT4, UCP2, and the lipid-processing proteins aP2 and HSL were down-regulated in hypoxic PAZ6 (Grosfeld et al., 2002).
The secretion of the leptin mutant R105W transfected in PAZ6 cells was impaired. Its retention by size-exclusion membranes that normally allow the elution of wild-type leptin suggests that the R105W form aggregates in the adipose cell (Boute et al., 2004).

PAZ6 cells express the human mRNA splice variant of the leptin receptor gene encoding a protein designated "leptin receptor gene-related protein" (OB-RGRP) distinct from the classic leptin receptor (OB-R; Bailleul et al., 1997). OB-RGRP was suggested to negatively regulate the function of the OB-R by decreasing its cell surface expression levels (Couturier et al., 2007). Hence, its expression might regulate leptin activity with consequent implications for the biology of PAZ6 cells.

\section{NUCLEAR RECEPTORS}

In PAZ6, peroxisome proliferator-activated receptor gamma coactivator 1-alpha $(\mathrm{PGCl} \alpha)$-dependent increase in UCP1 gene expression by retinoic acid (RA) or TZD (Oberkofler et al., 2002) has been observed, while a PPAR $\alpha$-specific agonist WY14,643 failed to regulate the expression of the UCP1 gene unless combined with RA (Oberkofler et al., 2002).

The UCP1 promoter is known to contain an enhancer region $3.7 \mathrm{~kb}$ upstream of the transcription initiation site containing several putative nuclear receptors (Cao et al., 2004; Collins et al., 2010). Specifically, a 221 bp region, $2.5 \mathrm{kbp}$ upstream of the start codon, contains a PPAR $\gamma$ (PPRE), cis-acting cAMP (CREB), and thyroid hormone (TRE) response elements. Retinoic acid receptor (RAR) was also described to mediate increased UCP1 expression, even though RA levels do not rise in the cold. PPAR $\alpha$ is regulated by cold and has been associated with increased UCP1 levels (Cao et al., 2004; Collins et al., 2010). The finding that the latter was not sufficient for the UCP1 gene activation is suggestive of the complex interplay between the several promoter receptors, transcriptional factors and cofactors. To explain the lack of effect of WY14,643 alone, it was hypothesized that in non-stimulated states - PPAR $\alpha$ binds a putative repressor forming a complex that could dissociate in the presence of $\mathrm{p} 38$ mitogen-activated protein kinases (p38 MAPK) signaling. Confirming this hypothesis, Oberkofler et al. (2002) showed that a MAPK-specific inhibitor (SB202190) completely abolished the stimulatory response seen in the PGC1 $\alpha$-dependent UCP1 promoter activity of cells treated with the combination RA/WY14,643 (Oberkofler et al., 2002).

Inhibition of the p38 MAP kinase signaling pathway with the same inhibitor was shown to impair PAZ6 adipocyte differentiation in an independent study (Zilberfarb et al., unpublished results; Figure 4).

The ratio of sterol regulatory element-binding protein $1 \mathrm{a} / 1 \mathrm{c}$ (SREBP1a/1c) in cells lines compared to primary tissues (spleen excluded) such as liver, adipose, adrenals, and others is inverted (Shimomura et al., 1997). This inverted pattern was also detected in PAZ6 cells, where the ratio SREBP1a/1c equals to 14. Predominance of the 1a isoform has been also found in 3T3-L1 cells where the 1c isoform is in fact, undetectable. 3T3-L1 differentiation results in an additional several fold increase in SREBP1a levels, with SREBP 1c remaining below the detection threshold. In PAZ6 co-transfected with PGC1a/SREBP1c Luc-reporter, treatment with liver $\mathrm{X}$ receptor (LXR)/retinoid X receptor (RXR) 


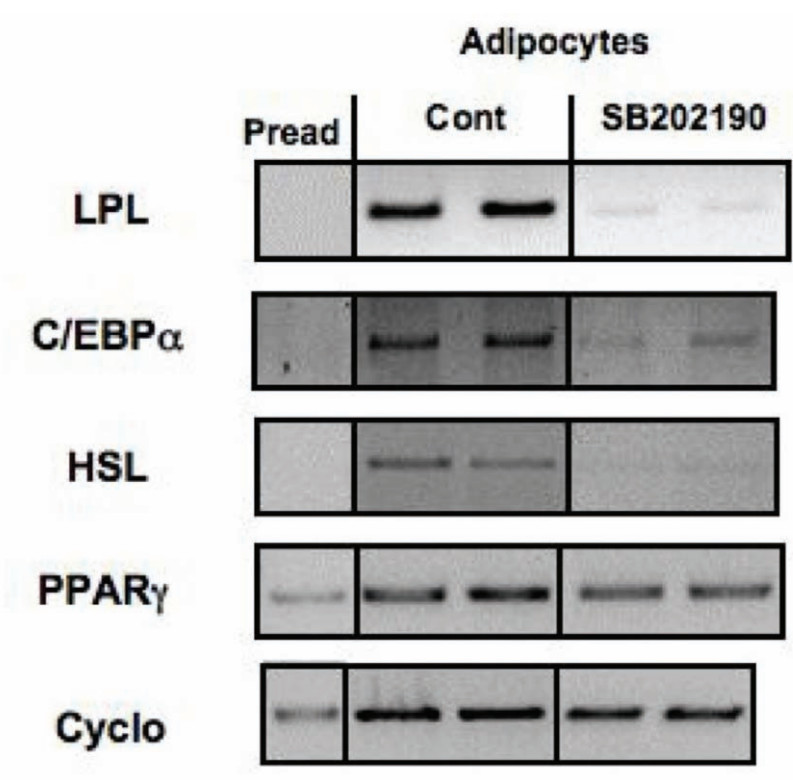

FIGURE 4 | Effect of inhibition of p38 MAP kinase on the expression of adipocyte differentiation markers in PAZ6 cells. PAZ6 pre-adipocytes (Pread) were cultured during 1 week in differentiation medium containing or not of the p38 inhibitor SB2022190 (10 mM). mRNA was then extracted and the expression of adipocyte differentiation markers was evaluated by RT-PCR as described by Zilberfarb et al. (1997).

agonists cells increased the activity of the SREBP1c promoter (Oberkofler et al., 2004b), leading to the interpretation that low LXR activity, due to low PGC1 $\alpha$ content might be the cause of the SREBP isoform ratio inversion of cell lines. The isoform 1a is much more active in stimulating transcription from SRE-1-containing promoters and was described to stimulate cholesterol metabolism-related genes (HMG CoA synthase, HMG CoA reductase, and LDL receptor) with greater ability than fatty acid metabolism-related ones (fatty acid synthase, acetyl CoA carboxylase, and LPL). This predominance of SREBP1a in vitro could be attributed to the elevated cholesterol demand of rapidly proliferating cultured cells, a relationship yet to be investigated.

\section{COMPARATIVE cDNA MICROARRAY ANALYSIS VERSUS LISA-2}

A comparative microarray study between the PAZ6 and Lisa2 cell lines (and between those and WAT) was performed by Van Beek et al. (2008). The authors firstly identified, through a cDNA subtraction strategy, the 30 most discriminating genes between WAT and two non-adipose tissues (lung and colon). Subsequently, by comparative cDNA microarray analysis, the percent expression of those cDNA's by PAZ6 and Lisa-2 cells relative to WAT was calculated. In both cell lines most of those highly discriminating, adipose-enriched genes were detected, several of which were, as expected, up-regulated by differentiation. Importantly, the gene expression pattern of the Lisa-2 cell line was reported to resemble WAT more closely than the PAZ6 (Van Beek et al., 2008). However, as a cDNA library of BAT was not established in parallel to WAT, the particular distinction between the respective white and brown features of the Lisa- 2 and the PAZ6 cells was not addressed. Nonetheless, the study confirmed the similarities among the human adipose cell lines and the primary tissue and helped differentiate genes expressed in all three adipocyte-derived cells from those found in non-adipose tissues.

\section{OTHERS ADIPOSE TISSUE FEATURES OF PAZ6 CELLS}

In agreement with two other studies on the effects of the steroid hormone dehydroepiandrosterone (DHEA) on human pre-adipocytes, the proliferation of PAZ6 cells, tested in parallel with 3T3-L1 and human primary pre-adipocytes, was significantly inhibited (Rice et al., 2010). The effect was observed in both cell lines under a $24 \mathrm{~h}$ exposure of $100 \mathrm{nM}$ to $100 \mu \mathrm{M}$ DHEA. Intraadipocyte DHEA concentration is an order of magnitude higher than the circulating levels which are within the nanomolar range, so the concentrations used in those test were within physiological levels (Rice et al., 2010).

The transcriptional activity of the wild-type or a variant UCP2 promoter was analyzed in PAZ6 cells. The common G/A polymorphism was shown to be associated with a $22 \%$ increase in transcriptional activity in differentiated but not in PAZ6 pre-adipocytes (Esterbauer et al., 2001).

The glycoprotein 130 ligands oncostatin M, interleukin-6, and cardiotrophin-1 increased several fold the secretion of the vascular endothelial growth factor (VEGF) in PAZ6 pre-adipocytes (4, 3.5 , and 3-fold, respectively) and adipocytes (3.5, 2, and 2-fold, respectively), in line with findings obtained from adipose tissue ex vivo, subcutaneous and visceral pre-adipocytes (Rega et al., 2007).

\section{FUTURE PERSPECTIVES}

Uncoupling protein 1 confers to mammals the ability to functionally cope with low ambient temperatures (Nicholls, 2001; Klingenspor et al., 2008). Thought to have first appeared in placental mammals, this transporter was later found to possess orthologs in marsupials and even ectotherm vertebrates (Nicholls, 2001; Klingenspor et al., 2008). Whether a thermogenic function holds true in these other vertebrates requires direct testing. Nevertheless, in the adequately clothed adult human, this perhaps dispensable thermogenic capacity has recently been recognized as an attractive anti-obesity target. Its potential to increase energy dissipation with no physical effort strongly appeals to the medical community, as compliance with standard diet and exercise recommendations is generally low. The benefits of increased BAT capacity further extend to improved clearance of circulating glucose and lipids (Bartelt et al., 2011; Orava et al., 2011) in a fashion analogous to the contracting skeletal musculature (Ivy, 1997).

It is, however, important to distinguish BAT mass from BATderived energy expenditure increase. While in cold adaptation, energy expenditure raises in parallel with BAT mass (Rothwell and Stock, 1984; Ouellet et al., 2011), the manipulation of BAT mass through specific drugs or genetic interventions can only translate into increased energy expenditure if all the components of the tissue's thermogenic machinery are active. Some of these components are yet to be uncovered. 
Table 2 | Brown adipose-specific, adipose-specific, and other PAZ6 cells features.

\begin{tabular}{ll}
\hline PAZ6 Brown adipose features & Reference \\
\hline UCP1 expression & Zilberfarb et al. (1997) \\
Multilocular fat accumulation & Zilberfarb et al. (1997) \\
$\beta_{3}$-AR predominance & Jockers et al. (1998) \\
PAZ6 ADIPOSE FEATURES & \\
aP2, PPAR $\gamma$, C/EBP- $\alpha$, HSL, LPL, leptin, & Zilberfarb et al. (1997) \\
GLUT1, and GLUT4 presence & \\
$\beta_{1}, \beta_{2}$, and $\beta_{3}$-AR expression and & Zilberfarb et al. (1997) \\
$\beta$-adrenergic-coupled lipolysis & \\
PPAR $\gamma$-sensitive differentiation & Strobel et al. (1999) \\
Melatonin receptor expression (isoform & Brydon et al. (2001) \\
MT2, found in BAT) & \\
OTHER PAZ6 FEATURES & \\
Transfectable & Oberkofler et al. (2002, 2004a,b) \\
Anti-proliferative response to DHEA & Rice et al. (2010) \\
\hline
\end{tabular}

A human brown adipose cell model, such as the PAZ6 cells, could become an essential tool to address these relevant questions: what conditions contribute to persistence of the "BAT-like" phenotype or protection from apoptosis? What factors stimu-

\section{REFERENCES}

Bailleul, B., Akerblom, I., and Strosberg, A. D. (1997). The leptin receptor promoter controls expression of a second distinct protein. Nucleic Acids Res. 25, 2752-2758.

Bartelt, A., Bruns, O. T., Reimer, R., Hohenberg, H., Ittrich, H., Peldschus, K., Kaul, M. G., Tromsdorf, U. I., Weller, H., Waurisch, C., Eychmüller, A., Gordts, P. L., Rinninger, F., Bruegelmann, K., Freund, B., Nielsen, P., Merkel, M., and Heeren, J. (2011). Brown adipose tissue activity controls triglyceride clearance. Nat. Med. 17, 200-205.

Betz, M. J., and Enerbäck, S. (2011). Therapeutic prospects of metabolically active brown adipose tissue in humans. Front. Endocrinol. 2:86. doi:10.3389/fendo.2011.00086

Blin, N., Nahmias, C., Drumare, M. F., and Strosberg, A. D. (1994). Mediation of most atypical effects by species homologues of the beta 3adrenoceptor. Br. J. Pharmacol. 112, 911-919.

Boute, N., Zilberfarb, V., Camoin, L., Bonnafous, S., Le Marchand-Brustel, Y., and Issad, T. (2004). The formation of an intrachain disulfide bond in the leptin protein is necessary for efficient leptin secretion. Biochimie 86, 351-356.

Brydon, L., Petit, L., Delagrange, P., Strosberg, A. D., and Jockers, R. (2001). Functional expression of

late nutrient catabolism and subsequent UCP1-mediated proton leak? What are the signaling pathways involved in thermogenic activation? Are there highly specific compounds with agonistic activity for such pathways? What constitutes the BAT "secretome"? Can BAT-cells be successfully engineered for transplantation in humans? Would individuals receiving BAT surgically become less cold-sensitive as possibly are those who naturally possess larger BAT depots?

\section{CONCLUSION}

The PAZ6 studies compiled to date include a significant list of BAT-specific characteristics (Table 2). The biological significance of the UCP1 levels expressed by differentiated PAZ6 adipocytes deserves to be better explored. The proper assessment of uncoupled respiration in PAZ6 cells will provide definite support to the relevance of the gene expression and morphology data. Continuous characterization will further support the use of PAZ6 cell line as a bona fide human brown adipocyte model and increase the number of its potential applications.

\section{ACKNOWLEDGMENTS}

We are grateful to the Landenberger foundation for a grant supporting the work on the PAZ6 cells. This is manuscript \# 21497 from The Scripps Research Institute.

Kahn, C. R. (2009). Identification and importance of brown adipose tissue in adult humans. N. Engl. J. Med. 360, 1509-1517.

Darimont, C., Zbinden, I., Avanti, O., Leone-Vautravers, P., Giusti, V., Burckhardt, P., Pfeifer, A. M., and Macé, K. (2003). Reconstitution of telomerase activity combined with HPV-E7 expression allow human preadipocytes to preserve their differentiation capacity after immortalization. Cell Death Differ. 10, 1025-1031.

Elabd, C., Chiellini, C., Carmona, M. Galitzky, J., Cochet, O., Petersen, R., Pénicaud, L., Kristiansen, K., Bouloumié, A., Casteilla, L., Dani, C., Ailhaud, G., and Amri, E. Z. (2009). Human multipotent adiposederived stem cells differentiate into functional brown adipocytes. Stem Cells 27, 2753-2760.

Esterbauer, H., Oberkofler, H., Krempler, F., Strosberg, A. D. and Patsch, W. (2000). The uncoupling protein-3 (UCP3) gene is transcribed from tissue-specific promoters in humans, but not in rodents. $J$. Biol. Chem. 275, 36394-36399.

Esterbauer, H., Schneitler, C., Oberkofler, H., Ebenbichler, C., Paulweber, B., Sandhofer, F., Ladurner, G., Hell, E., Strosberg, A. D., Patsch, J. R., Krempler, F., and Patsch, W. (2001). A common polymorphism in the promoter of UCP2 is associated with decreased risk of obesity in middle-aged humans. Nat. Genet. 28, 178-183.

Festuccia, W. T., Blanchard, P. G., Richard, D., and Deshaies, Y. (2010). Basal adrenergic tone is required for maximal stimulation of rat brown adipose tissue UCP1 expression by chronic PPARgamma activation. Am. J. Physiol. Regul. Integr. Comp. Physiol. 299, R159-R167.

Gilsanz, V., Chung, S. A., Jackson, H., Dorey, F. J., and Hu, H. H. (2011). Functional brown adipose tissue is related to muscle volume in children and adolescents. J. Pediatr. 158, 722-726.

Grosfeld, A., Zilberfarb, V., Turban, S., Andre, J., Guerre-Millo, M., and Issad, T. (2002). Hypoxia increases leptin expression in human PAZ6 adipose cells. Diabetologia 45, 527-530.

Hazan, U., Romero, I. A., Cancello, R., Valente, S., Perrin, V., Mariot, V., Dumonceaux, J., Gerhardt, C. C., Strosberg, A. D., Couraud, P. O., and Pietri-Rouxel, F. (2002). Human adipose cells express CD4, CXCR4, and CCR5 [corrected] receptors: a new target cell type for the immunodeficiency virus-1? FASEB J. 16, 1254-1256.

Himms-Hagen, J. (1999). Physiological roles of the leptin endocrine system: differences between mice and humans. Crit. Rev. Clin. Lab. Sci. 36, 575-655. 
Hirschberg, V., Fromme, T., and Klingenspor, M. (2011). Test systems to study the structure and function of uncoupling protein 1: a critical overview. Front. Endocrinol. 2:63. doi:10.3389/fendo.2011.00063

Hu, H. H., Chung, S. A., Nayak, K. S., Jackson, H. A., and Gilsanz, V. (2011). Differential computed tomographic attenuation of metabolically active and inactive adipose tissues: preliminary findings. J. Comput. Assist. Tomogr. 35, 65-71.

Hu, H. H., and Gilsanz, V. (2011). Developments in the imaging of brown adipose tissue and its associations with muscle, puberty, and health in children. Front. Endocrinol. 2:33. doi:10.3389/fendo.2011.00033

Lean, M. E., James, W. P., Jennings, G., and Trayhurn, P. (1986). Brown adipose tissue uncoupling protein content in human infants, children and adults. Clin. Sci. 71, 291-297.

Hu, H. H., Smith, D. L. Jr., Nayak, K. S., Goran, M. I., and Nagy, T. R. (2010a). Identification of brown adipose tissue in mice with fat-water IDEALMRI. J. Magn. Reson. Imaging 31, 1195-1202.

Hu, H. H., Smith, D. L. Jr., Goran, M. I., Nagy, T. R., and Nayak, K. S. (2010b). Characterization of brown adipose tissue in mice with IDEAL fat-water MRI. Proc. Int. Soc. Magn. Reson. Med. 18, 749 .

Hugo, E. R., Brandebourg, T. D., Comstock, C. E., Gersin, K. S., Sussman, J. J., and Ben-Jonathan, N. (2006). LS14: a novel human adipocyte cell line that produces prolactin. Endocrinology 147, 306-313.

Irie, Y., Asano, A., Canas, X., Nikami, H., Aizawa, S., and Saito, M. (1999). Immortal brown adipocytes from p53-knockout mice: differentiation and expression of uncoupling proteins. Biochem. Biophys. Res. Commun. 255, 221-225.

Ivy, J. L. (1997). Role of exercise training in the prevention and treatment of insulin resistance and non-insulindependent diabetes mellitus. Sports Med. 24, 321-336.

Jockers, R., Issad, T., Zilberfarb, V., de Coppet, P., Marullo, S., and Strosberg, A. D. (1998). Desensitization of the beta-adrenergic response in human brown adipocytes. Endocrinology 136, 2676-2684.

Klein, J., Fasshauer, M., Klein, H. H., Benito, M., and Kahn, C. R. (2002). Novel adipocyte lines from brown fat: a model system for the study of differentiation, energy metabolism, and insulin action. Bioessays 24, 382-388.

Klingenspor, M., Fromme, T., Hughes DA, J. r., Manzke, L., Polymeropoulos, E., Riemann, T., Trzcionka, M., Hirschberg, V., and Jastroch, M. (2008). An ancient look at UCP1. Biochim. Biophys. Acta 1777, 637-641.

Lafontan, M., and Berlan, M. (1993). Fat cell adrenergic receptors and the control of white and brown fat cell function. J. Lipid Res. 34, 1057-1091.

Lath, N., Familua, O., Adu, A., and Oluwole, S. (2011). Massive abdominal wall hibernoma: case report and literature review of a rare soft-tissue tumor. J. Natl. Med. Assoc. 103, 372-374.

Lee, P., Swarbrick, M. M., Zhao, J. T., and Ho, K. K. (2011). Inducible brown adipogenesis of supraclavicular fat in adult humans. Endocrinology 152, 3597-3602.

Morganstein, D. L., Wu, P., Mane, M. R., Fisk, N. M., White, R., and Parker, M. G. (2010). Human fetal mesenchymal stem cells differentiate into brown and white adipocytes: a role for ERR alpha in human UCP1 expression. Cell Res. 20, 434-444.

National Institutes of Health. (2010). U.S. Department of Health and Human Services, Overweight and Obesity Statistics. Bethesda: Weightcontrol Information Network.

Nedergaard, J., Bengtsson, T., and Cannon, B. (2007). Unexpected evidence for active brown adipose tissue in adult humans. Am. J. Physiol. Endocrinol. Metab. 293, E444-E452.

Nedergaard, J., Bengtsson, T., and Cannon, B. (2011). New powers of brown fat: fighting the metabolic syndrome. Cell Metab. 13, 238-240.

Nicholls, D. G. (2001). A history of UCP1. Biochem. Soc. Trans. 29(Pt 6), 751-755.

Oberkofler, H., Esterbauer, H., Linnemayr, V., Strosberg, A. D., Krempler, F., and Patsch, W. (2002). Peroxisome proliferator-activated receptor (PPAR) gamma coactivator-1 recruitment regulates PPAR subtype specificity J. Biol. Chem. 277, 16750-16757.

Oberkofler, H., Linnemayr, V., Weitgasser, R., Klein, K., Xie, M., Iglseder, B., Krempler, F., Paulweber, B., and Patsch, W. (2004a). Complex haplotypes of the PGC- $1 \alpha$ gene are associated with carbohydrate metabolism and type 2 diabetes. Diabetes 53, 1385-1393.

Oberkofler, H., Schraml, E., Krempler, F., and Patsch, W. (2004b).
Restoration of sterol-regulatoryelement-binding protein-1c gene expression in HepG2 cells by peroxisome-proliferator-activated receptor-gamma co-activator-1 alpha. Biochem. J. 381( $\mathrm{Pt} 2)$, 357-363.

Orava, J., Nuutila, P., Lidell, M. E. Oikonen, V., Noponen, T., Viljanen, T., Scheinin, M., Taittonen, M., Niemi, T., Enerbäck, S., and Virtanen, K. A. (2011). Different metabolic responses of human brown adipose tissue to activation by cold and insulin. Cell Metab. 14, 272-279.

Ouellet, V., Routhier-Labadie, A., Bellemare, W., Lakhal-Chaieb, L., Turcotte, E., Carpentier, A. C., and Richard, D. (2011). Outdoor temperature, age, sex, body mass index, and diabetic status determine the prevalence, mass, and glucose-uptake activity of $18 \mathrm{~F}$ FDG-detected BAT in humans. J. Clin. Endocrinol. Metab. 96 192-199.

Penfornis, P., Viengchareun, S., Le Menuet, D., Cluzeaud, F., Zennaro, M. C., and Lombes, M. (2000). The mineralocorticoid receptor mediates aldosterone-induced differentiation of T37i cells into brown adipocytes. Am. J. Physiol. Endocrinol. Metab. 279, E386-E394.

Rega, G., Kaun, C., Demyanets, S., Pfaffenberger, S., Rychli, K., Hohensinner, P. J., Kastl, S. P., Speidl, W. S., Weiss, T. W., Breuss, J. M. Furnkranz, A., Uhrin, P., Zaujec, J., Zilberfarb, V., Frey, M., Roehle, R., Maurer, G., Huber, K., and Wojta, J. (2007). Vascular endothelial growth factor is induced by the inflammatory cytokines interleukin6 and oncostatin $\mathrm{M}$ in human adipose tissue in vitro and in murine adipose tissue in vivo. Arterioscler. Thromb. Vasc. Biol. 27, 1587-1595.

Rice, S. P., Zhang, L., GrennanJones, F., Agarwal, N., Lewis, M. D., Rees, D. A., and Ludgate, M. (2010). Dehydroepiandrosterone (DHEA) treatment in vitro inhibits adipogenesis in human omental but not subcutaneous adipose tissue. Mol. Cell. Endocrinol. 320 51-57.

Ross, S. R., Choy, L., Graves, R. A., Fox, N., Solevjeva, V., Klaus, S., Ricquier, D., and Spiegelman, B. M. (1992). Hibernoma formation in transgenic mice and isolation of a brown adipocyte cell line expressing the uncoupling protein gene. Proc. Natl. Acad. Sci. U.S.A. 89, 7561-7565.
Rothwell, N. J., and Stock, M. J. (1981). Regulation of energy balance. Annu. Rev. Nutr. 1, 235-256.

Rothwell, N. J., and Stock, M. J. (1984). Effects of denervating brown adipose tissue on the responses to cold, hyperphagia and noradrenaline treatment in the rat. J. Physiol. (Lond.) 355, 457-463.

Saito, M., Okamatsu-Ogura, Y., Matsushita, M., Watanabe, K., Yoneshiro, T., Nio-Kobayashi, J., Iwanaga, T., Miyagawa, M., Kameya, T., Nakada, K., Kawai, Y., and Tsujisaki, M. (2009). High incidence of metabolically active brown adipose tissue in healthy adult humans: effects of cold exposure and adiposity. Diabetes 58, 1526-1531.

Seale, P., Bjork, B., Yang, W., Kajimura, S., Chin, S., Kuang, S., Scimè, A. Devarakonda, S., Conroe, H. M., Erdjument-Bromage, H., Tempst, P., Rudnicki, M. A., Beier, D. R., and Spiegelman, B. M. (2008). PRDM16 controls a brown fat/skeletal muscle switch. Nature 454, 961-967.

Shimomura, I., Shimano, H., Horton, J. D., Goldstein, J. L., and Brown, M. S. (1997). Differential expression of exons 1a and $1 \mathrm{c}$ in mRNAs for sterol regulatory element binding protein1 in human and mouse organs and cultured cells. J. Clin. Invest. 99, 838-845.

Strobel, A., Siquier, K., Zilberfarb, V., Strosberg, A. D., and Issad, T. (1999). Effect of thiazolidinediones on UCP2 expression in human PAZ-6 adipocytes. Diabetologia 42 , 527-533.

Svensson, P. A., Jernås, M., Sjöholm, K., Hoffmann, J. M., Nilsson, B. E., Hansson, M., and Carlsson, L. M. (2011). Gene expression in human brown adipose tissue. Int. J. Mol. Med. 27, 227-232.

Tang, W., Zeve, D., Suh, J. M. Bosnakovski, D., Kyba, M., Hammer, R. E., Tallquist, M. D., and Graff, J. M. (2008). White fat progenitor cells reside in the adipose vasculature. Science 322, 583-586.

Tontonoz, P., and Spiegelman, B. M. (2008). Fat and beyond: the diverse biology of PPARgamma. Annu. Rev. Biochem. 77, 289-312.

Torii, I., Morikawa, S., Nakano, A., and Morikawa, K. (2003). Establishment of a human preadipose cell line, HPB-AML-I: refractory to PPARgamma-mediated adipogenic stimulation. J. Cell. Physiol. 197, $42-52$.

Van Beek, E. A., Bakker, A. H. Kruyt, P. M., Vink, C., Saris, W. 
H., and Keijer, J. (2008). Comparative expression analysis of isolated human adipocytes and the human adipose cell lines LiSa2 and PAZ6. Int. J. Obes. 32, 922-929.

van Marken Lichtenbelt, W. D. (2011). Human brown fat and obesity: methodological aspects. Front. Endocrinol. 2:52. doi:10.3389/fendo.2011.00052

van Marken Lichtenbelt, W. D., Vanhommerig, J. W., Smulders, N. M., Drossaerts, J. M., Kemerink, G. J., Bouvy, N. D., Schrauwen, P., and Teule, G. J. (2009). Cold-activated brown adipose tissue in healthy men. N. Engl. J. Med. 360, 1500-1508. [Erratum in: N. Engl. J. Med. 360, 1917].

Vitic, J., and Stevanovic, J. (1993). Comparative studies of the serum lipoproteins and lipids in some domestic, laboratory and wild animals. Comp. Biochem. Physiol. B 106, 223-229.
Wabitsch, M., Brenner, R. E., Melzner, I., Braun, M., Möller, P., Heinze, E., Debatin, K. M., and Hauner, H. (2001). Characterization of a human preadipocyte cell strain with high capacity for adipose differentiation. Int. J. Obes. Relat. Metab. Disord. 25, 8-15.

Wabitsch, M., Brüderlein, S., Melzner, I., Braun, M., Mechtersheimer, G., and Möller, P. (2000). LiSa-2, a novel human liposarcoma cell line with a high capacity for terminal adipose differentiation. Int. J. Cancer 88, 889-894.

Waldén, T. B., Hansen, I. R., Timmons, J. A., Cannon, B., and Nedergaard, J. (2012). Recruited vs. nonrecruited molecular signatures of brown, "brite," and white adipose tissues. Am. J. Physiol. Endocrinol. Metab. 302, E19-E31.

Wibmer, C., Leithner, A., Zielonke, N., Sperl, M., and Windhager, R. (2010). Increasing incidence rates of soft tissue sarcomas? A population-based epidemiologic study and literature review. Ann. Oncol. 21, 1106-1111.

World Health Organization. (2010). Ten Facts on Obesity. Available at: http:// www.who.int/features/factfiles/ obesity/en/

Zilberfarb, V., Piétri-Rouxel, F., Jockers, R., Krief, S., Delouis, C., Issad, T., and Strosberg, A. D. (1997). Human immortalized brown adipocytes express functional beta3-adrenoceptor coupled to lipolysis. J. Cell Sci. 110, 801-807.

Zilberfarb, V., Siquier, K., Strosberg, A. D., and Issad, T. (2001). Effect of dexamethasone on adipocyte differentiation markers and tumour necrosis factor alpha expression in human PAZ6 cells. Diabetologia 44, 377-386.

Conflict of Interest Statement: The authors declare that the research was conducted in the absence of any commercial or financial relationships that could be construed as a potential conflict of interest.

Received: 25 October 2011; accepted: 14 January 2012; published online: 02 February 2012.

Citation: Kazantzis M, Takahashi V, Hinkle J, Kota S, Zilberfarb V, Issad $T$, Abdelkarim M, Chouchane $L$ and Strosberg AD (2012) PAZ6 cells constitute a representative model for human brown pre-adipocytes. Front. Endocrin. 3:13. doi: 10.3389/fendo.2012.00013

This article was submitted to Frontiers in Cellular Endocrinology, a specialty of Frontiers in Endocrinology.

Copyright (c) 2012 Kazantzis, Takahashi, Hinkle, Kota, Zilberfarb, Issad, Abdelkarim, Chouchane and Strosberg. This is an open-access article distributed under the terms of the Creative Commons Attribution Non Commercial License, which permits non-commercial use, distribution, and reproduction in other forums, provided the original authors and source are credited. 